\title{
Hypoxia activates the cyclin D1 promoter via the Jak2/STAT5b pathway in breast cancer cells
}

\author{
Youn Hee Joung ${ }^{1}$, Eun Joung Lim ${ }^{1}$, \\ Moon Young Lee ${ }^{1}$, Jong-Hwan Park ${ }^{3}$, \\ Sang-Kyu Ye ${ }^{4}$, Eui U Park ${ }^{1}$, \\ Sang Yoon $\mathrm{Kim}^{1}$, Zheng Zhang ${ }^{5}$, \\ Kwang Jeon Lee ${ }^{6}$, Dong Ki Park ${ }^{7}$, \\ Taekyu Park ${ }^{2}$, Won Kook Moon ${ }^{8}$ \\ and Young Mok Yang ${ }^{1,9}$
}

${ }^{1}$ Department of Pathology, College of Medicine and Bio-Food and Drug Research Center

Konkuk University

${ }^{2}$ Bio-Food and Drug Research Center

Department of Biotechnology

College of Biomedical and Health Science

Konkuk University

Chungju 380-701, Korea

${ }^{3}$ Oral and Pharyngeal Cancer Branch, NIDCR

$\mathrm{NIH}$, Bethesda, MD 20892-4340, USA

${ }^{4}$ Department of Pharmacology

Seoul National University College of Medicine

Seoul 110-799, Korea

${ }^{5}$ Laboratory of Kidney and Electrolyte Metabolism, NHLBI

$\mathrm{NIH}$, Bethesda, MD 20892-1603, USA

${ }^{6}$ Department of Animal Biotechnology

College of Animal Husbandry

${ }^{7}$ Department of Applied Biology and Chemistry

Konkuk University, Seoul 143-701, Korea

${ }^{8}$ Natural F\&P Corp. O-Chang Science Industry Plaza

Chongwon 363-883, Korea

${ }^{9}$ Corresponding author: Tel, 82-43-840-3754;

Fax, 82-43-851-9329; E-mail, ymyang@kku.ac.kr

Accepted 22 July 2005

Abbreviations: DFO, desferrioxamine; EMSA, electrophoretic mobility shift assay; GAS, IFN- $\gamma$-activated sequence; IP, immunoprecipitation; Jak2, Janus kinase 2; STAT, signal transducers and activators of transcription

\footnotetext{
Abstract

Hypoxia, a common consequence of solid tumor growth in breast cancer or other cancers, serves to propagate a cascade of molecular pathways which include angiogenesis, glycolysis, and various cellcycle control proteins. As we have shown previously,
}

hypoxia activates STAT5 (signal transducer and activator of transcription 5) and increases its binding activity to the GAS element in mammary epithelial cells. In this study we attempted to elucidate the mechanism by which cyclin D1 is regulated by the STAT5 protein under hypoxic conditions. Our data demonstrate that hypoxia $\left(2 \% \mathrm{O}_{2}\right)$ or desferrioxamine (DFO) induces tyrosine and serine phosphorylation of STAT5 in human breast cancer cells (MCF-7) and mammary epithelial cells (HC11). Imunoprecipitation and subsequent Western analysis showed that Jak2 leads to the tyrosine phosphorylation and activation of STAT5a or STAT5b under hypoxic conditions. Using a transfected COS-7 cell model system, we demonstrate that the activity of a cyclin D1 promoter-luciferase construct increased under hypoxic conditions or DFO treatment. The activity of the STAT5b/cyclin D1 promoter increased significantly by $12 \mathrm{~h}$ of hypoxia, whereas the activity of the STAT5a/cyclin D1 promoter was unaffected under hypoxic conditions. These increases in promoter activity are predominantly mediated by the Jak2/ STAT5b signaling pathway. We have shown by EMSA that hypoxia induces STAT5 to bind to the cyclin D1 promoter (GAS-1) in MCF-7 and HC11 cells. These data suggest that STAT5b may mediate the transcriptional activation of cyclin D1 after hypoxic stimulation.

Keywords: breast neoplasms; cell hypoxia; cyclin D1; Janus kinase 2; Stat5 protein; trans-activation

\section{Introduction}

Hypoxia is a stress that causes alterations in signal transduction and gene instability. In the cancer microenvironment, hypoxia plays a significant role in forming a tumor phenotype and tumor progression (Bando et al., 2003). Hypoxia results in adaptive changes in the transcription of a wide range of genes involved either in increasing the availability of oxygen to the tissues or in decreasing the cellular consumption of oxygen by activating glycolysis (BrahimiHorn et al., 2001). Most solid tumors contain hypoxic components (Harris, 2002). Recent reports revealed that the status of hypoxia in tumor tissue is a marker of poor prognosis in several types of solid cancers, including breast cancer (Schindl et al., 2002). Most of 
these cancers overexpress cyclin D1, a component of the cell-cycle machinery (Yu et al., 2001). D-type cyclins are active in the $\mathrm{G} 1$ phase of the cell cycle, where they complex with cyclin-dependent kinases (cdks) to catalyze the transition from the $\mathrm{G} 1$ to $\mathrm{S}$ phase of the cell cycle. Cyclin D1 is critical for lobuloalveolar proliferation in the mammary gland during pregnancy. However, overexpression of cyclin D1, as is seen in approximately $50 \%$ of human mammary tumors (Bartkova et al., 1994; Yu et al., 2001), leads to mitogenesis in mammary tumor cells in culture (Musgrove et al., 1994; Kim et al., 2003). This can also be seen in transgenic mice, where targeted overexpression of cyclin D1 in mammary epithelial cells leads to tumor formation (Wang et al., 1994). These observations suggest that strict control of cyclin D1 expression in mammary epithelial cells is necessary to separate normal development from oncogenesis (Brockman et al., 2002). Thus, two central processes in tumor biology appear to be hypoxia and cyclin D1 overexpression.

STATs (signal transducers and activators of transcription) may affect proliferation by regulating the expression of immediate-early genes, such as c-myc and $c$-fos, as well as cell cycle regulatory genes, such as the cyclins (Bowman et al., 2000). The Jak/STAT pathways are activated by various growth factors and cytokines. Binding of these cytokines to their receptors activates the Jak tyrosine kinases, followed by tyrosine phosphorylation of the receptors. This leads to activation and homo- or heterodimerization of the STAT5 transcription factors, translocation into the nucleus, and activation of target genes (Bienvenu et al., 2001). The products of the closely related $(<90 \%$ identical) and chromosomally linked STAT5a and $-5 b$ genes are activated by a wide range of cytokines (O'Shea et al., 2002). Despite the approximately 95\% amino acid identity between STAT5a and $-5 b$ and their redundant roles in regulating blood and immune cell function, the two transcription factors also appear to have functional differences (Grimley et al., 1999). For instance, STAT5b is selectively important for growth hormone signaling (Udy et al., 1997), whereas STAT5a is particularly critical for prolactin-induced mammary gland differentiation (Liu et al., 1997; Yamashita et al., 2001).

We recently demonstrated that desferrioxamine (DFO) or hypoxia activates STAT5 and enhances its binding to the IFN- $\gamma$ activated sequence (GAS) sequence in the $\beta$-casein gene promoter in mammary epithelial cells (Joung et al., 2003). DFO, that mimics hypoxia and a similar oxygen sensor in the hypoxia regulation, induces a hypoxic condition (Tazuke et al., 1998; Park et al., 2000; Park et al., 2001a). The effect of DFO on DNA synthesis and repair was reflected in studies that have shown that treatment with DFO induces apoptosis in rapidly growing tumor cells (Fukuchi et al., 1994; Simonart et al., 2000). This new finding indicates that there is another pathway that is different from the HIF-1 signaling pathway, which is known as a major mechanism in hypoxia signaling.

STAT5 proteins activate the expression of the cyclin D1 gene through the recognition of a conserved element in the promoter (Bromberg et al., 1999; Matsumura et al., 1999). As one of the target genes activated by the STAT cascade, cyclin D1 is probably an important mediator of the STAT-dependent growth of hematopoietic cells. However, the exact role of this protein in this signaling pathway remains to be determined. We postulated that the activated form of STAT5 due to hypoxia may contribute to one level of control by modulation of the transcriptional activity of the cyclin D1 promoter. However, surprisingly, we observed differences in transcriptional activities of STAT5a and $-5 b$ induced by hypoxia. It is known that ligand-dependent and -independent signal transduction pathways may differentially regulate STAT5a and $-5 b$ nuclear translocation and, therefore, have the potential to differentially regulate STAT5-dependent gene expression (Kazansky et al., 1999).

In this paper, we attempted to elucidate the mechanism by which cyclin D1 is regulated by STAT5b protein under hypoxic conditions. The form of STAT5b activated by hypoxia was found to recognize specifically a STAT5-responsive element in the promoter of cyclin D1 expression. Thus STAT5b appears to mediate transcriptional activation of cyclin D1 by hypoxia in human breast cancer cells. These findings contribute to our understanding of the role that STAT5b in mediating the transcriptional activation of cyclin D1 by hypoxia, and may ultimately improve the therapy of solid cancers, including human breast cancer.

\section{Materials and Methods}

\section{Materials}

The cyclin D1 antibody (MS-210-P1) was purchased from Neomarkers (Fremont, CA). STAT antibodies (STAT5a, sc-1081; STAT5b, sc-1656; STAT5, sc-835) were from Santa Cruz Biotechnology (Santa Cruz, CA). Anti-Jak2 antibody, anti-phospho-STAT5a/b (Y694/Y699), anti-phospho-STAT5a/b (S726/S731) and anti-phosphotyrosine monoclonal antibody 4G10 were from Upstate Biotechnology (Lake Placid, NY). Anti-actin antibody, FBS, insulin, EGF, DFO and an immunoprecipitation kit (IP-50) were obtained from Sigma Chemical Co. (St. Louis, MO). AG490 was from Calbiochem (San Diego, CA). The luciferase assay substrates, reporter lysis buffer and electrophoretic mobility shift assay (EMSA) kit were purchased from Promega Corp. (Madison, WI). FuGene 
6 transfection reagent was from Roche (Basel, Switzerland). HRP-conjugated donkey anti-rabbit IgG, HRP-conjugated goat anti-mouse lgG, enhanced chemilumiescence (ECL) detection kit and $\left[\gamma_{-}{ }^{32} \mathrm{P}\right] \mathrm{ATP}$ were purchased from Amersham Pharmacia Biotech. (Piscataway, NJ). Restore Western blot stripping buffer was from Pierce (Rockford, IL). The oligonucleotide probes for EMSA analysis were synthesized by Bioneer (Daejeon, Korea).

\section{Cell culture and transient transfection}

HC11, mouse mammary epithelial cells, were grown to confluency in RPMI 1640 medium containing 10\% FBS, insulin $(5 \mu \mathrm{g} / \mathrm{ml})$, and EGF (10 $\mathrm{ng} / \mathrm{ml})$. MCF-7, human breast cancer cells, and COS-7 cells were cultured in DMEM containing 10\% FBS, 2 mM glutamine, and $100 \mathrm{U} / \mathrm{ml}$ penicillin and streptomycin at $37^{\circ} \mathrm{C}$ in $5 \% \mathrm{CO}_{2}$. At the initiation of each experiment, the cells were resuspended in the medium at a density of $2.5 \times 10^{5}$ cells $/ \mathrm{ml}$. For hypoxic conditions, the cells were placed in airtight chambers (NuAire, Plymouth, MN), which were flushed with a $5 \% \mathrm{CO}_{2}$ I $95 \% \mathrm{~N}_{2}$ mixture until the oxygen concentration was $2 \%$. For transfection, the COS-7 cells into $35-\mathrm{mm}$ culture dishes were transfected with DNA constructs $(1.3 \mu \mathrm{g})$ using the FuGene 6 according to the manufacturer's recommendation.

\section{Expression vectors and construction of plasmid vector}

The expression vectors for mouse STAT5a and STAT5b (pMX/STAT5a and pMX/STAT5b; kindly provided by Dr. Koichi Ikuta, Kyoto University, Japan) were constructed as previously described (Joung et al., 2003). A series of 5' promoter reporter constructions derived from the human cyclin D1 genomic clone were previously described (Albanese et al., 1995).

\section{Luciferase assays}

For reporter gene assays, COS-7 cells were transiently co-transfected with the cyclin D1 (GAS1) construct (Albanese et al., 1995) and the STAT5a or STAT5b expression vector (Joung et al., 2003). Transfected cells were washed twice with ice-cold PBS, and $150 \mu \mathrm{l}$ of lysis buffer was added to the wells. Lysates were then used directly to measure luciferase activity. For luciferase assays, $100 \mu$ of cell lyastes were mixed with $350 \mu$ of assay buffer containing $25 \mathrm{mM}$ glycylglycine, $\mathrm{pH} 7.8,15 \mathrm{mM}$ $\mathrm{MgSO}_{4}, 4 \mathrm{mM}$ EGTA, $5 \mathrm{mM}$ ATP, and $1 \mathrm{mM}$ DTT. Luciferase activity of each sample was determined by measuring luminescence for $10 \mathrm{~s}$ on a Lumat LB 9507 luminometer (EG\&G Berthold, Oak Ridge, TN) after injection of $100 \mu$ of $1 \mathrm{mM}$ luciferine. The experiments were performed in triplicate, and similar results were obtained from at least three independent experiments.

\section{Immunoprecipitation and Western blotting}

Whole cell extracts (WCE) from HC11 cells and MCF-7 cells were prepared by lysing cells in RIPA buffer (50 mM Tris-HCl, pH 7.5, 5 mM EDTA, 150 mM $\mathrm{NaCl}$, and $1 \%$ Triton $\mathrm{X}-100)$ containing protease and phosphatase inhibitors ( $1 \mathrm{mM}$ PMSF, $2 \mu \mathrm{g} / \mathrm{ml}$ leupeptin, $4 \mu \mathrm{g} / \mathrm{ml}$ aprotinin, and $1 \mu \mathrm{g} / \mathrm{ml}$ pepstatin). For immunoprecipitation, $500 \mu \mathrm{g}$ of WCE was incubated with $4 \mu \mathrm{l}$ anti-Jak2 or anti-phospho-STAT5 (Y694/ Y699) antibodies for $1 \mathrm{~h}$ at $4^{\circ} \mathrm{C}$. Protein $\mathrm{G}$ agarose beads were added, and the mixture was incubated overnight at $4^{\circ} \mathrm{C}$ on a rocking platform. The beads were washed four times in $1 \times I P$ buffer, resuspended in $2 \times$ electrophoresis sample buffer, and boiled for $5 \mathrm{~min}$. The WCE (20 $\mu$ l per each lane) or immunoprecipitated proteins were subjected to SDSPAGE and electrophoretically transferred onto a nitrocellulose membrane. Western blots were performed as described previously (Joung et al., 2003). After blocking the residual binding sites on the filter, immunoblotting was performed with an appropriate antibody.

\section{Oligonucleotide labeling and electrophoretic mobility shift assay (EMSA)}

The GAS1 probe consisted of a synthetic doublestranded oligonucleotide corresponding to the sequence 5'-CGTGGAGTTCTTGGAAATGCGCC-3'. To assay for competition of GAS1 binding, a mutant double-stranded GAS1 oligonucleotide (5'-GTGCCCTCGTGGAGCCCTTGGAAATGCGC-3'), or double stranded nonspecific SP-1 and AP-2 were used. The double-stranded DNA probe was end-labeled using $\mathrm{T}_{4}$ polynucleotide kinases and $\left[\gamma^{32} \mathrm{P}\right] \mathrm{ATP}$ and used in all EMSAs. EMSAs were performed as described previously (Joung et al., 2003). For supershift assays, $1 \mu \mathrm{g}$ of antibody was incubated with nuclear extracts for $20 \mathrm{~min}$ on ice before the addition of radiolabeled probe.

\section{Data analysis}

The results of the experiments are expressed as mean \pm SEM. A statistical analysis was performed with ANOVA test. This was compared by one-way analysis of variance followed by Duncan's multiple range test. Values were considered high significantly different at $P<0.001$. 


\section{Results}

Importance of transcriptional control of cyclin D1 expression in human breast cancer cells (MCF-7) in response to DFO

As shown in Figure 1, the levels of cyclin D1 were increased in MCF-7 cells after $6 \mathrm{~h}$ of DFO treatment (upper panel). Pretreatment of the cells with actinomycin $D$ to block transcription, resulted in a decrease in basal cyclin D1 protein levels. Actinomycin D treatment also prevented the DFO-induced increase in cyclin D1 protein levels (lanes 3 and 4), which is consistent with an effect at the level of transcription. In contrast, the levels of $\beta$-actin are not altered by

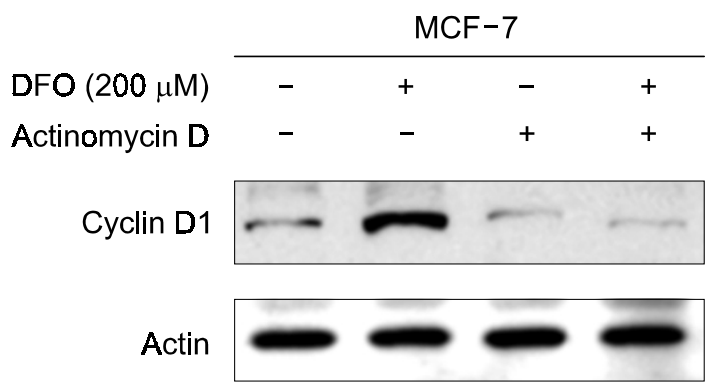

Figure 1. Importance of transcriptional control of cyclin D1 expression in human breast cancer cells (MCF-7) in response to DFO. Representative Western blot analysis of cyclin D1 and $\beta$-actin in cell lysates. Cells were incubated $\pm 10 \mu \mathrm{g}$ actinomycin $\mathrm{D}$ for $1 \mathrm{~h}$, then treated with $200 \mu \mathrm{M}$ DFO for an additional $6 \mathrm{~h}$.
DFO treatment, and the greater stability of this protein is reflected in the lack of effect of actinomycin $D$ at the $6 \mathrm{~h}$ time point (lower panel).

\section{Cyclin D1 protein levels in breast cancer cells after DFO or hypoxia treatment}

Because cyclin D1 has the key role in regulating the G1/S transition and mediating the response to other growth factors, we examined the effect of DFO or hypoxia on cyclin D1 protein levels. The expression of cyclin D1 was increased by treatment with DFO or hypoxia via dose and time dependent manner in HC11 and MCF-7 cells, a maximum increase was seen after $6 \mathrm{~h}$ of DFO or hypoxia stimulation (Figure 2 ). These results clearly show that the cyclin D1 is increased by DFO or hypoxia in mammary epithelial cells (HC11) and human breast cancer cells (MCF-7).

\section{Stimulation of tyrosine phosphorylation Jak2 and STAT5 proteins in breast cancer cells by DFO or hypoxia}

To determine whether the activity of Jak2 is required for DFO- or hypoxia-stimulated STAT5 activation or not, we examined the tyrosine phosphorylation status of STAT5 in HC11 and MCF-7 cells. Phospho-Jak2 was detected by immunoblotting with anti-phosphotyrosine (4G10) antibody after Jak2 immunoprecipitation. Phospho-STAT5 was detected with anti-phospho-STAT5 (Y694/Y699) antibody without immunoprecipitation. As shown in Figure 3A, Jak2 tyrosine

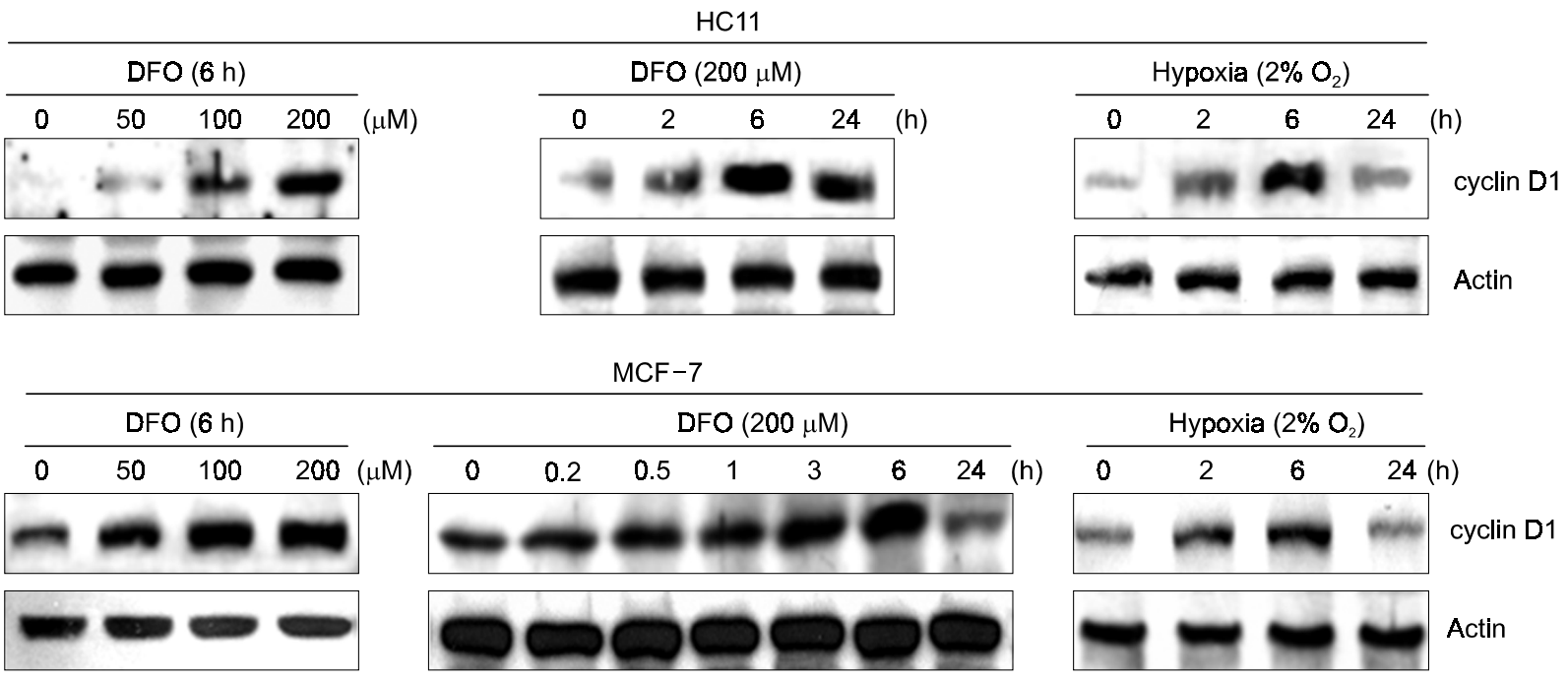

Figure 2. Cyclin D1 protein levels after treatment with DFO or hypoxia. The levels of cyclin D1 in mammary epithelial cells (HC11, upper panel) and human breast cancer cells (MCF-7, lower panel), after the time/dose course of DFO or hypoxia as indicated. Cell lysates were separated on $12 \%$ SDS-PAGE and transferred to a nitrocellulose membrane. The membrane was blotted with the anti-cyclin D1 antibody, then stripped and reprobed with the anti-actin antibody. 
phosphorylation and STAT5 phosphorylation reached a maximum after $6 \mathrm{~h}$ of DFO or hypoxia stimulation in HC11 and MCF-7. These results indicate that DFO or hypoxia induces tyrosine phosphorylation of Jak2, which may then activate phosphorylation of the STAT5. These findings are consistent with the involvement of Jak2 in DFO or hypoxia stimulation of cyclin D1 expression via phosphorylation of STAT5.

\section{A}

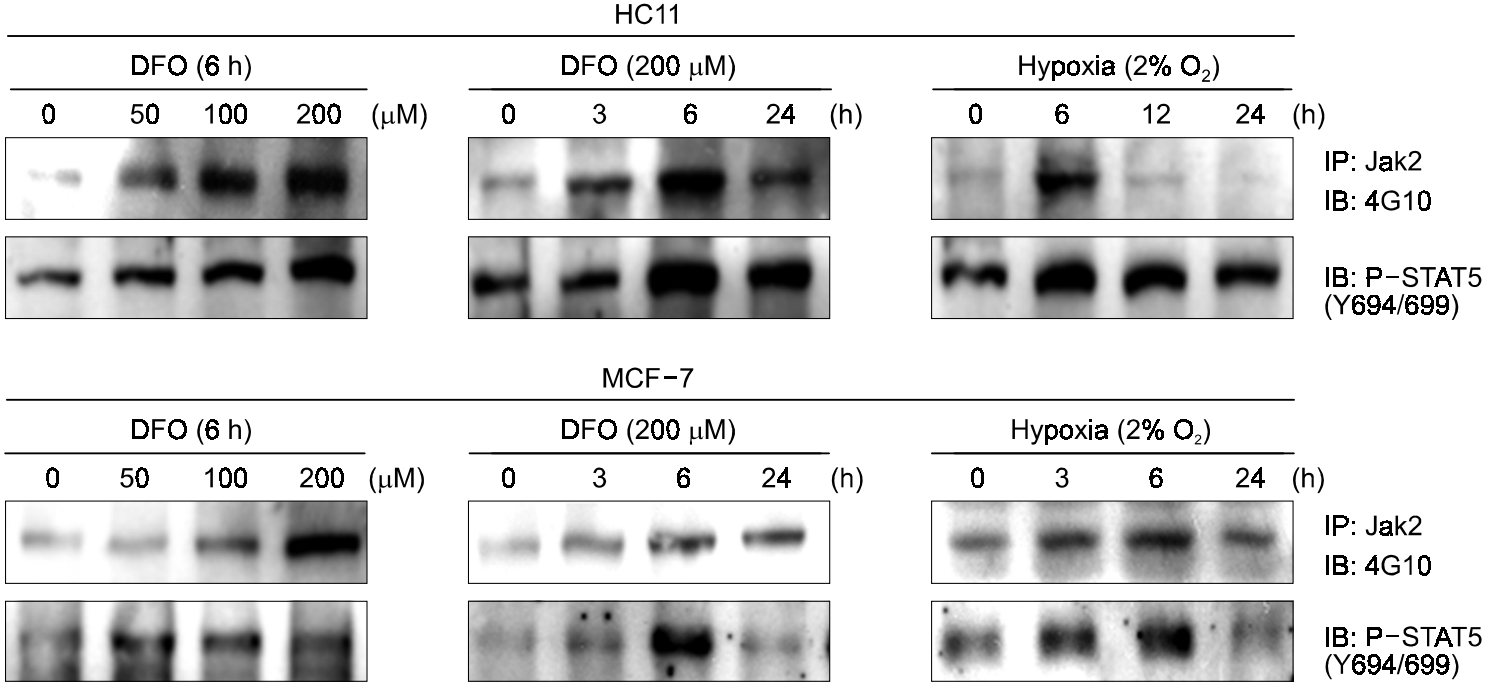

B
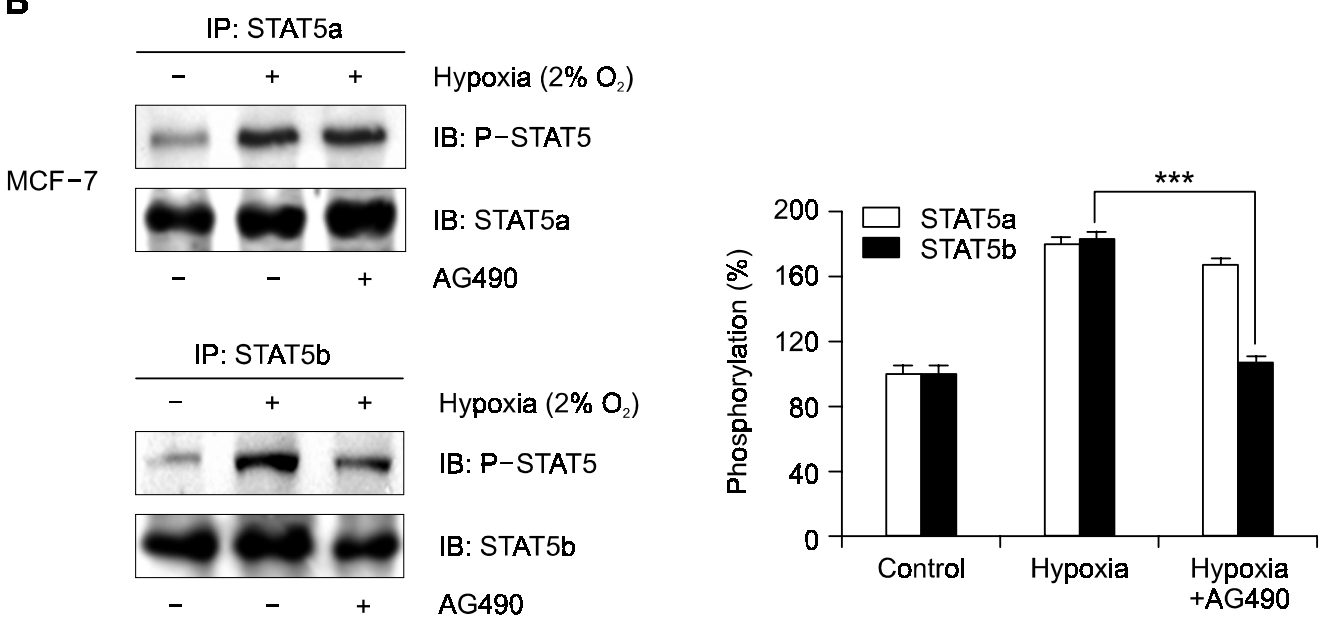

Figure 3. The activation of tyrosine and serine phosphorylation of STAT5 by DFO or hypoxia. (A) Activation of tyrosine-phosphorylated Jak2 and STAT5 proteins by DFO or hypoxia in mammary epithelial cells (HC11) and human breast cancer cells (MCF-7), over the time/dose course as indicated. Cell lysates were immunoprecipitated using anti-Jak2 antibody. The immuno complexes were separated on 8\% SDS-PAGE and transferred to a nitrocellulose membrane. Phospho-Jak2 was detected by immunoblotting with anti-phosphotyrosine (4G10) antibody after Jak2 immunoprecipitation. In contrast, phospho-STAT5 was detected without immunopreciptiation with an anti-phospho-STAT5 (Y694/699) antibody. The tyrosine phospho-STAT5 antibody could not distinguish between P-STAT5a and P-STAT5b. (B) Effects of AG490, a Jak2 kinase inhibitor, on hypoxia $\left(2 \% \mathrm{O}_{2}\right)$ stimulation of STAT5 expression and its phosphorylation. Human breast cancer cells (MCF-7) were treated with hypoxia for $6 \mathrm{~h}$ following a $4 \mathrm{~h}$ pretreatment with AG490 (50 $\mu \mathrm{M})$. STAT5a and STAT5b were immunoprecipitated with specific antibodies, and Western blotting was performed using an antibody that recognizes the phosphorylated form (P-STAT5) of STAT5a (Y694) and STAT5b (Y699), and then with the same antibodies used for immunoprecipitation. Graphic data represent the mean of at least three separate experiments, mean \pm SEM. Asterisks indicate a statistically significant decrease by ANOVA test ${ }^{* * *} P<$ 0.001) in hypoxia with AG490 of MCF-7 cell line. (C) Serine phosphorylation of STAT5 by DFO or hypoxia in mammary epithelial cells (HC11) and human breast cancer cells (MCF-7), over the time course or concentration indicated. Cell lysates were separated on 8\% SDS-PAGE and transferred to a nitrocellulose membrane. The membrane was blotted with the anti-phospho-STAT5 (S726/731), then stripped and reprobed with the anti-STAT5 antibody. The serine phospho-STAT5 antibody could not distinguish between P-STAT5a and p-STAT5b. (D) Comparison between tyrosine and serine phosphorylation activities of STAT5 in animal cells (HC11) and human cells (MCF-7). Graphic data represent the mean of at least three separate experiments, mean \pm SEM. Y694/699, tyrosine 694/699. S726/731, serine 726/731. 
C

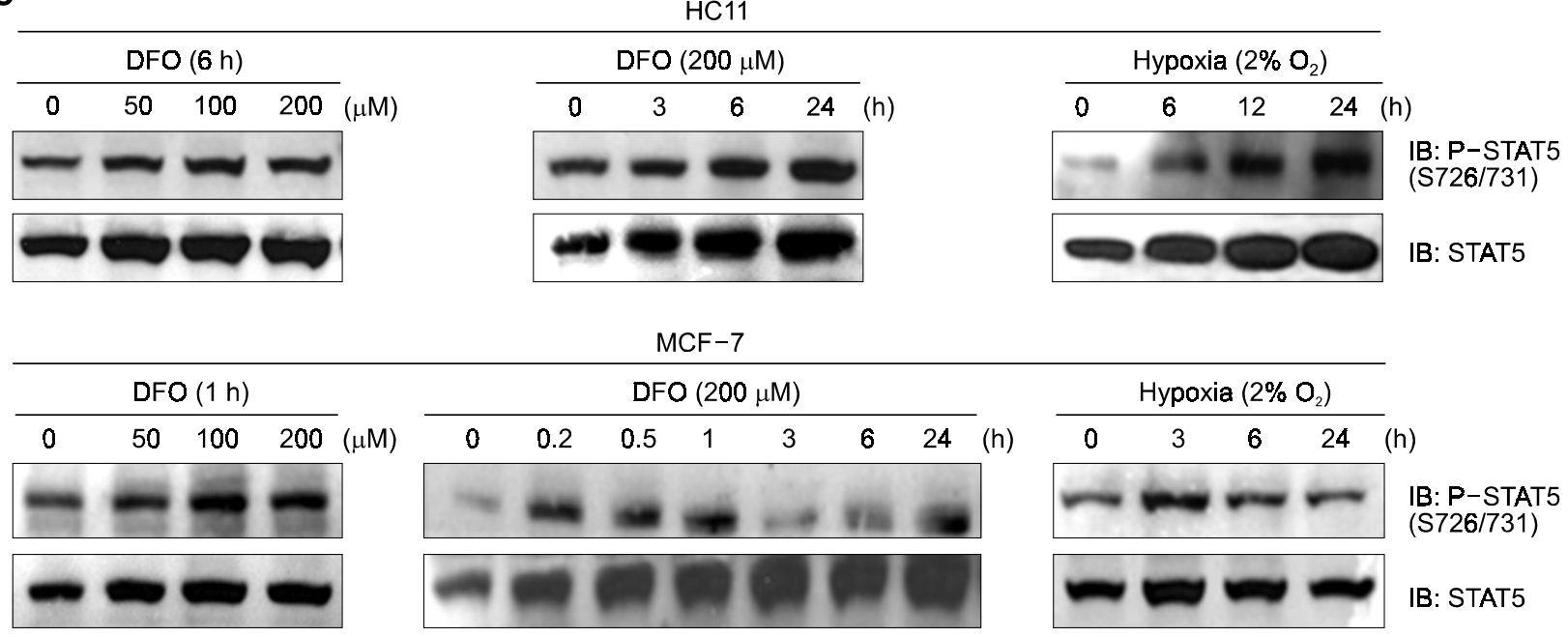
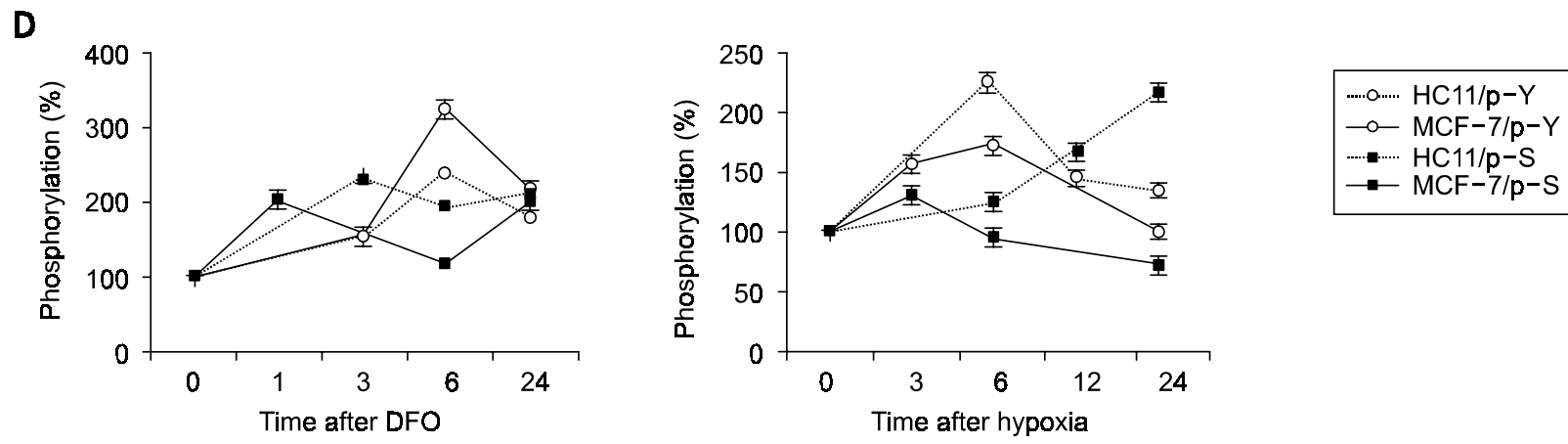

Figure 3. Continued from page 357.

\section{Inhibition of DFO- or hypoxia-induced STAT5 phosphorylation by AG490}

We investigated whether the effect of AG490 was due to its ability to block activation of STAT5. HC11 and MCF-7 cells were treated with DFO or hypoxia for $6 \mathrm{~h}$ following a $4 \mathrm{~h}$ pretreatment with AG490. STAT5a and $-5 b$ were then immunoprecipitated, and the extent of phosphorylation was examined by Western blotting. STAT5 became highly phosphorylated on Y694/Y699, in response to hypoxia in MCF-7 cells (Figure 3B, 2nd lanes). However, hypoxia-induced phosphorylation of only STAT5b was prevented by AG490, whereas the phosphorylation of STAT5a was not affected in human breast cancer cells (Figure 3B, upper panel). These results suggest that Jak2 appears to be sufficient for hypoxia activation of STAT5b, whereas a second tyrosine kinase may be involved in hypoxia activation of STAT5a. The inhibition of Jak2 by AG490 leads to a blockade of hypoxia-induced phosphorylation of STAT5b $(P<0.001)$ and partial inhibition of STAT5a $(P>0.05)$ in breast cancer cells (Figure 3B). These findings suggest that the activation of STAT5b is completely dependent on Jak2, whereas STAT5a can be activated by other kinases as well.

\section{Serine phosphorylation of STAT5 in breast cancer} cells after treatment with DFO or hypoxia

As we have shown previously, DFO or hypoxia induces the tyrosine phosphorylation of STAT5 in mammary epithelial cells (HC11) (Joung et al., 2003). To see whether serine phosphorylation of STAT5 is induced by DFO or hypoxia stimulation, we examined the serine phosphorylation status of STAT5 protein in HC11 and MCF-7 cells. The serine phosphorylation of STAT5 after DFO stimulation increased after $6 \mathrm{~h}$, and that by hypoxia stimulation was also time-dependently up-regulated in $\mathrm{HC} 11$ cells (Figure 3C, upper panel). On the other hand, an increase of STAT5 serine phosphorylation in MCF-7 cells was observed within $0.2 \mathrm{~h}$ after DFO and but was transient, and within $3 \mathrm{~h}$ of hypoxia (Figure 3C, lower panel). As compared with tyrosine phosphorylation, the induction of serine phosphorylation came more quickly (Figure 3D). These results indicate that DFO or hypoxia induces serine phosphorylation of STAT5 in mam- 
A

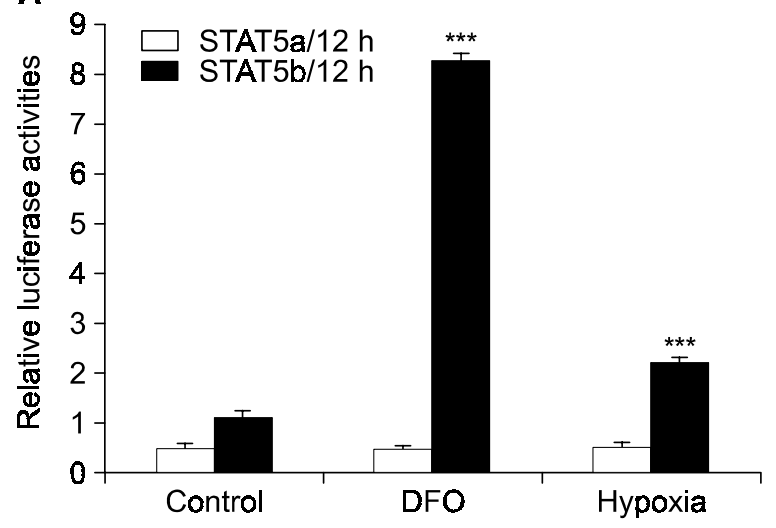

B

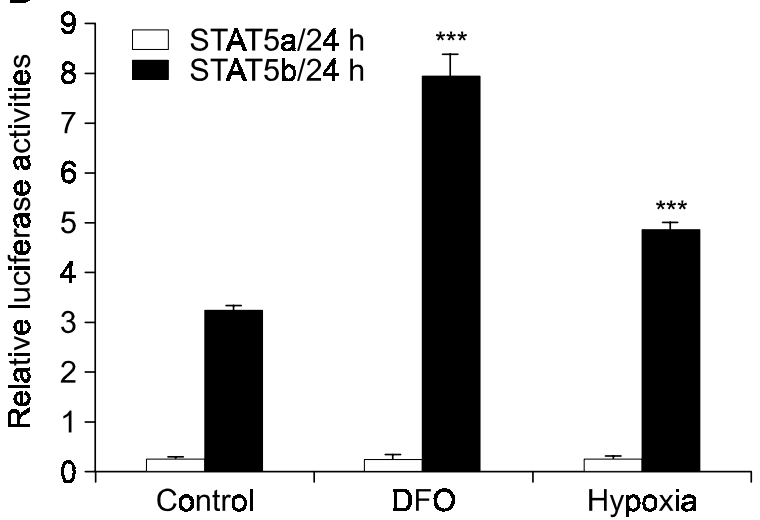

Figure 4. Activation of STAT5a/cyclin D1 and STAT5b/cyclin D1 promoter by DFO or hypoxia. COS-7 cells were transiently co-transfected with a cyclin D1 (GAS1) luciferase reporter gene and STAT5a (open bar) or STAT5b (solid bar) gene, and then cultured in serum-free media with DFO (200 $\mu$ M) or under hypoxic conditions $\left(2 \% \mathrm{O}_{2}\right)$ for (12 or $24 \mathrm{~h}(\mathrm{~A}$ and $\mathrm{B})$. Cell lysates were assayed for luciferase activity. Data represent the mean of at least three separate experiments, mean \pm SEM. Asterisks indicate a statistically significant increase by ANOVA tests (** $P<0.001)$ in DFO- or hypoxia-treated promoter activity compared with non-treated control.

A

\begin{tabular}{|c|c|}
\hline \multicolumn{2}{|c|}{ MCF-7 } \\
\hline DFO $(200 \mu \mathrm{M})$ & Hypoxia $\left(2 \% \mathrm{O}_{2}\right)$ \\
\hline $\begin{array}{llll}0 & 6 & 12 & 24 \\
(h)\end{array}$ & $\begin{array}{llll}0 & 6 & 12 & 24 \\
(h\end{array}$ \\
\hline
\end{tabular}
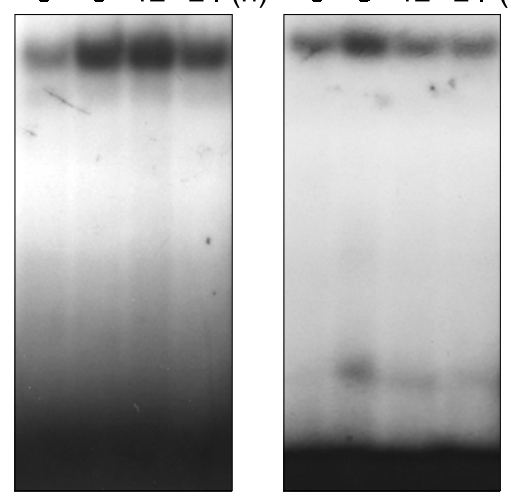

- DNA-STAT5
complex

- free probe
B

\begin{tabular}{|c|c|}
\hline \multicolumn{2}{|c|}{$\mathrm{HC} 11$} \\
\hline DFO $(200 \mu \mathrm{M})$ & Hypoxia $\left(2 \% \mathrm{O}_{2}\right)$ \\
\hline $\begin{array}{llll}0 & 6 & 12 & 24 \\
\end{array}$ & $\begin{array}{llll}0 & 6 & 12 & 24 \\
\end{array}$ \\
\hline
\end{tabular}
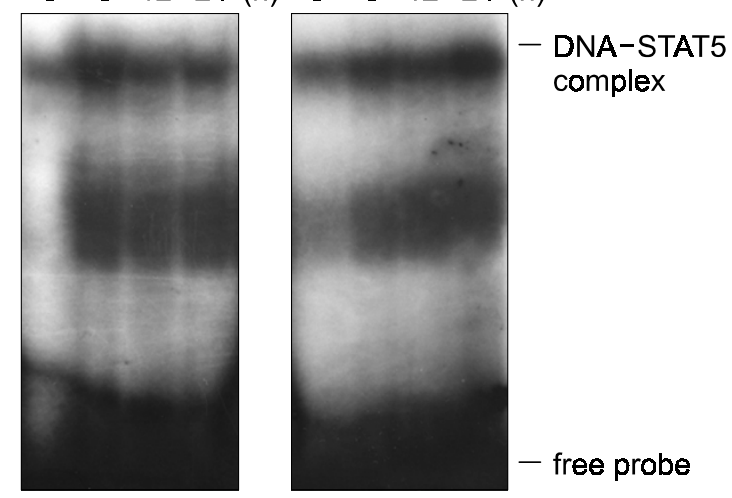

C
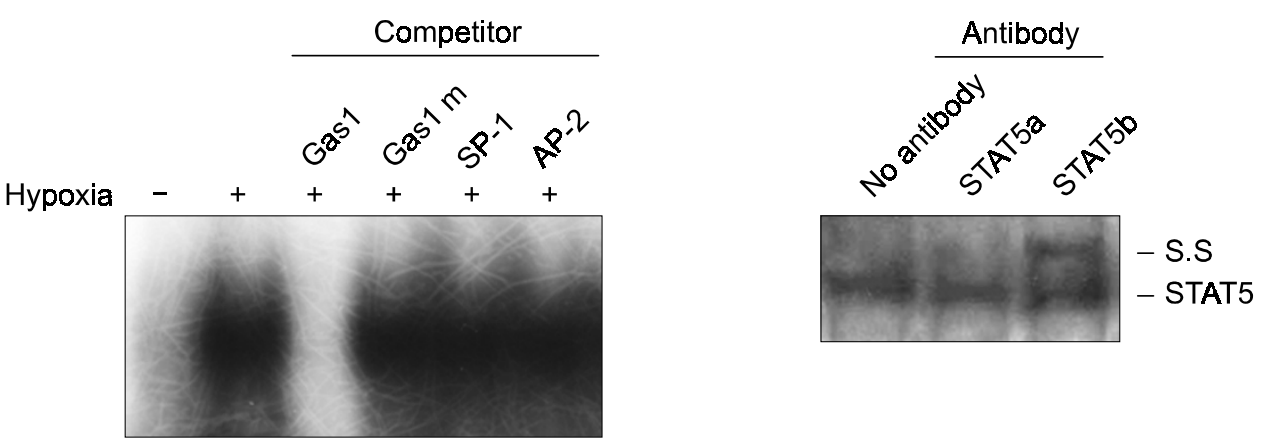

Figure 5. DFO or hypoxia induces binding of STAT5 to the cyclin D1-GAS1 site as shown by EMSA. (A and B) DNA-binding activities of STAT5 by DFO or hypoxia in human breast cancer cells (MCF-7) and mammary epithelial cells (HC11), over the time course as indicated. Nuclear extracts were prepared, and then were incubated with a ${ }^{32} \mathrm{P}$-labeled probe specific for the GAS1 site. The resulting complexes were electrophoresed in $6 \%$ non-denaturing gel. (C) Identification of the cyclin D1 (GAS1 site)-binding protein by EMSA. In competition assays, nuclear extracts were prepared, and then were incubated with a ${ }^{32} \mathrm{P}$-labeled probe specific for the GAS1 site. Some nuclear extracts were preincubated with unlabeled GAS1 probe, a mutated GAS1 probe, or unlabeled nonspeicific (SP1 and AP2) probe (left panel). In supershift assays, the nuclear proteins treated by hypoxia $\left(2 \% \mathrm{O}_{2}\right)$ were incubated with $1 \mu \mathrm{g}$ of anti-STAT5a and anti-STAT5b antibodies for $30 \mathrm{~min}$ at $4^{\circ} \mathrm{C}$, and then the binding reaction were performed (right panel). S. S, supershifted DNA binding complexes. 
mary epithelial cells and human breast cancer cells. In addition, we confirmed that STAT5 is constitutively activated in HC11 and MCF-7 cells (Figure 3C, lower band).

\section{DFO or hypoxia increases cyclin D1 promoter activity}

The effect of DFO or hypoxia on the transcriptional activation of cyclin D1 was examined using a human cyclin D1 promoter-luciferase construct, which contains a distal cyclin D1 promoter (GAS1) sequence upstream of a luciferase reporter. COS-7 cells were transiently co-transfected with the cyclin D1 (GAS1) construct and STAT5a or STAT5b, then cultured in serum-free media with DFO treatment or hypoxic conditions for different times (12 and $24 \mathrm{~h}$ ). As shown in Figure 4A, the relative luciferase activities of STAT5b/cyclin D1 promoter increased significantly after $12 \mathrm{~h}$ of DFO treatment or hypoxic conditions (solid bar, $P<0.001$ ), whereas the relative luciferase activities of STAT5a/cyclin D1 promoter were unaffected under DFO or hypoxic conditions (open bar). The trends for $24 \mathrm{~h}$ treatment were similar to $12 \mathrm{~h}$ (Figure 4A and B). As compared with control, the relative luciferase activities of STAT5b/cyclin D1 (12 h) increased 7.5 folds with DFO treatment and 2 folds under hypoxic conditions. On the other hand, the relative luciferase activities in STAT5a/cyclin D1 (12 h) did not change (0.99 folds in DFO treatment and 1.1 folds under hypoxic conditions). These results suggest that the STAT5b protein may be a critical mediator of the STAT5/cyclin D1 pathway by DFO or hypoxia.

\section{DFO or hypoxia induces binding of STAT5 to the cyclin D1-GAS1 site}

The Jak-STAT signal transduction pathway influences normal cell survival and growth mechanisms and may contribute to oncogenic transformation. Activated STATs form dimers, translocate to the nucleus, bind to specific response elements in the promoters of target genes, and transcriptionally activate these genes (Joung et al., 2003). STAT5 recognizes the GAS sequence in the promoter of cyclin D1 by PRL (Brockman et al., 2002). DFO or hypoxia induces binding of nuclear proteins to GAS1, as demonstrated by EMSA, which is consistent with its role in mediating DFO or hypoxia signals. Extracts from MCF-7 and HC11 cells treated with DFO or hypoxia show lower mobility complexes compared with extracts from untreated cells. As shown in Figure $5 \mathrm{~A}$, the STAT5 DNA-binding activities reached a maximum after $12 \mathrm{~h}$ by DFO but after $6 \mathrm{~h}$ by hypoxia in MCF-7 cells. In HC11 cells, the STAT5 DNA-binding activities peaked after $24 \mathrm{~h}$ by hypoxia (Figure $5 \mathrm{~B}$ ). The results show that DFO or hypoxia induced STAT5 DNAbinding activities in MCF-7 cells and HC11 cells. To investigate the binding specificity of the protein competition, EMSAs with unlabeled GAS1, mutated GAS1 and nonspecific SP-1 and AP-2 consensus nucleotides as probes were performed with nuclear extracts from DFO-treated MCF-7 cells. Figure 5C, left panel

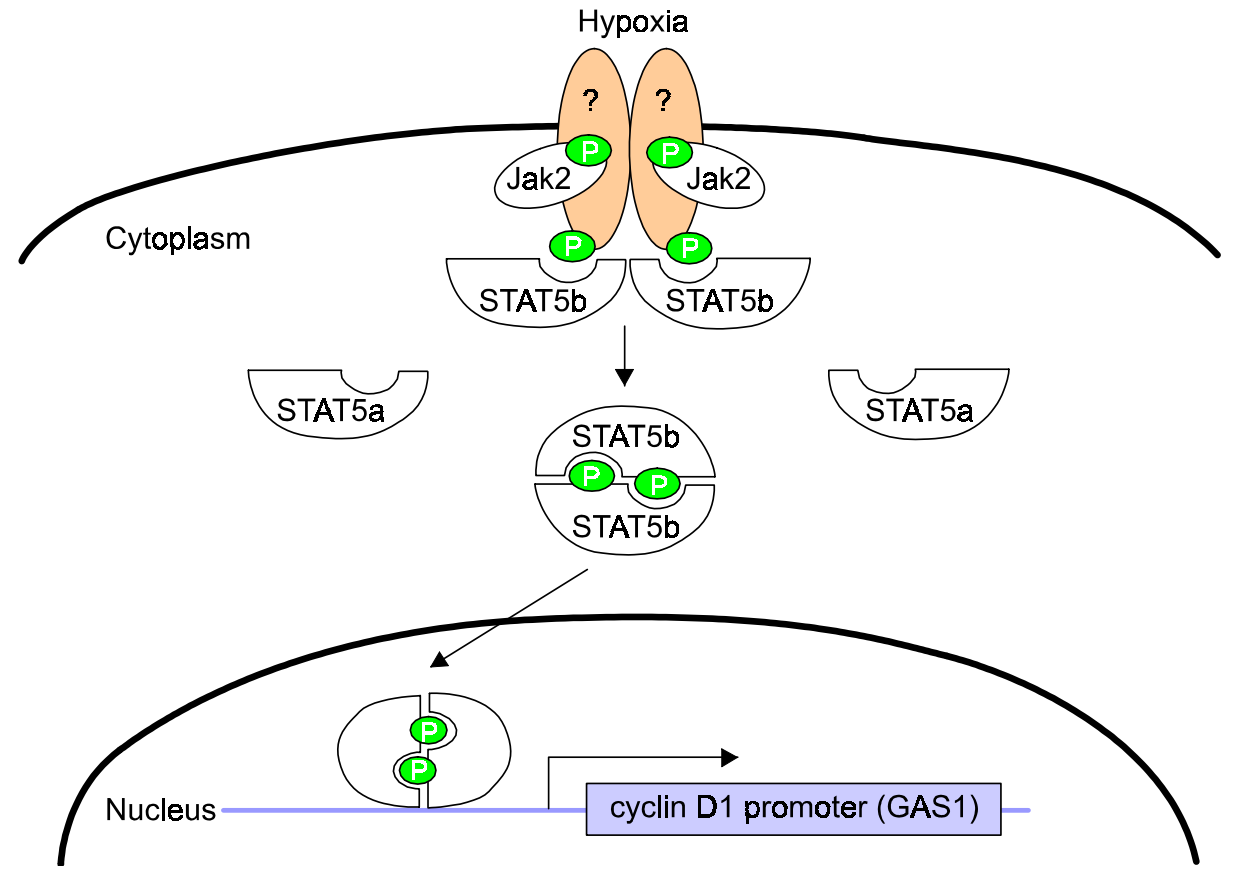

Figure 6. Schematic representation of Jak2/STAT5b signaling for cyclin D1 expression in response to hypoxia in breast cancer cells. Hypoxia can induce elevation of cyclin D1 protein and accumulation of cyclin D1 in the nucleus via the Jak2/ STAT5b pathway. However, it is uncertain what receptor is involved. The relationship between hypoxia and cell stress is not clear. However our data were shown that breast cancer cells can maintain hypoxic condition and STAT5s are constitutively activated. P, phosphate. 
shows that a GAS1 consensus element efficiently inhibited binding, whereas an oligonucleotide containing mutated GAS1 and a nonspecific SP-1 or AP-2 oligonucleotide in molar excess did not compete for binding. To further identify the protein composition of the STAT5-binding complex, antibodies to STAT5a and $-5 b$ were used in a supershift analysis with nuclear extracts from hypoxia-treated MCF-7 cells. As shown in Figure $5 \mathrm{C}$, right panel, the polyclonal antibody to STAT5b shifted the complex, whereas STAT5a antibody had no effect.

\section{Discussion}

The results presented in this study describe a role for STAT5b, differentiated from STAT5a, in hypoxia stimulation of cyclin D1 transactivation in breast cancer cells. We have shown that STAT5b mediates and regulates the transactivation of cyclin D1 by hypoxia stimulation in breast cancer cells, suggesting a novel biological role for STAT5b in the regulation of hypoxiasignaling pathways.

Our studies have shown that DFO-induced proliferation of mammary epithelial cells is associated with an increase in the expression of the cell cycle regulator, cyclin D1. Interestingly, there is no other current study demonstrating the effects of DFO on cyclin D1 protein levels in HC11 and MCF-7 cells. The increase in cyclin D1 expression seen here appears to occur at the level of transcription because treatment of cells with actinomycin D blocks the DFOinduced increase of cyclin D1 expression (Figure 1). DFO-induced cyclin D1 expression may be controlled at multiple levels, including transcription, RNA stability, translation, and protein degradation.

In recent studies, mitogen activation of cyclin D1 gene expression in breast cancer cells likely requires prevention of PDGF-induced cyclin D1 expression. It has been shown in other cell types that STATs are important in cyclin D1 gene expression (Bromberg et al., 1999; Matsumura et al., 1999; Simon et al., 2002). We have shown in the present studies that DFO or hypoxia increases the expression levels of cyclin D1 protein in breast cancer cells (Figure 2). STAT5 may contribute to the cyclin D1 up-regulation directly through STAT5 binding sites in the cyclin D1 promoter.

Jaks play a pivotal role in cytokine signaling. Because cytokine receptors lack intrinsic kinase activity, they rely on the constitutively associated Jaks to phosphorylate and active their STAT protein substrates (Ihle, 1995; Pellegrini and Dusanter-Fourt, 1997; Leonard and O'Shea, 1998). Whether Jak2 may be involved in the activation of signaling molecules in addition to STAT5, such as coactivators or other transcription factors, has not been investigated. In this study, we show that STAT5 activation by DFO or hypoxia can be Jak2 dependent (Figure 3A). Our data indicate that Jak2 kinase is required for STAT5 activation by hypoxia in breast cancer cells. Thus, STAT5 protein was tyrosine phosphorylated under hypoxic conditions. Although tyrosine phosphorylated STAT5 was detected upon DFO or hypoxia treatment, it was unclear initially which isoform (STAT5a or -5b) was phosphorylated. In recent studies, the ability of PRL to activate STAT5b phosphorylation through two kinases appears to be specific for STAT5b and not STAT5a. Very few instances of differential regulation of STAT5a and STAT5b have been reported; however, one, in particular, is of interest. Insulin can induce tyrosine phosphorylation of both STAT5a and STAT5b (Storz et al., 1999). AG490 prevented phosphorylation of STAT5a only and had no effect on STAT5b phosphorylation by insulin (Frasor et al., 2001). However, in the present study, AG490 prevented phosphorylation of only STAT5b and partially inhibited STAT5a phosphorylation by hypoxia (Figure 3B). These data suggest that Jak2 activity is required for hypoxia regulation of gene transcription in some fashion beyond its ability to induce STAT5b phosphorylation on Y699.

In addition to this Jak-catalyzed tyrosine phosphorylation reaction, STAT proteins may undergo serine phosphorylation. STAT5 serine phosphorylation may in part be mediated by the MAPK cascade, as suggested by binding interactions between STAT5a and the MAPKs ERK1 and ERK2 (Pircher et al., 1999). In recent studies, STAT nuclear translocation and DNA binding activity are generally not affected by STAT serine phosphorylation, but they are affected by STAT tyrosine phosphorylation (Park et al., 2001b). Our studies show that DFO or hypoxia induces serine phosphorylation of STAT5 in HC11 cells and MCF-7 cells (Figure $3 \mathrm{C}$ ). These results suggest that the activity of STAT5 protein can be induced by a serine kinase as well as by a tyrosine kinase in response to DFO or hypoxia stimulation (Figure 3D). Other work in our laboratory has shown that other STAT proteins, as well as STAT5, were tyrosine and serine phosphorylated by hypoxia in mouse and human breast cancer cells (Lee et al., 2005, data not shown).

STAT5 has been shown to mediate the transcriptional regulation of cyclin D1, thereby contributing to cytokine- and prolactin-dependent growth of hematopoietic and breast cancer cells, respectively (Matsumura et al., 1999; Schroeder et al., 2002). The cyclin D1 promoter contains binding sites for a number of transcription factors other than STAT5, whose activity may be modulated either directly or indirectly by Src kinase (Lee et al., 1999; Kabotyanski 
and Rosen, 2003). STAT5 may participate in hypoxia-induced cell growth through transcriptional regulation of cyclin $\mathrm{D} 1$, which plays a key role in both G1 progression and G1/S transition in the cell cycle. Consistent with this hypothesis, DFO- or hypoxiaactivated STAT5b, but not STAT5a, was able to transactivate the cyclin D1 promoter (Figure 4). Our data showing that the activity of a cyclin D1 promoter-luciferase reporter construct is enhanced by DFO or hypoxia stimulation in the COS-7 cell system provides additional evidence that DFO or hypoxia can modulate the transcriptional activity of cyclin D1 (Figure 4). This is an important step in understanding the mitogenic response to hypoxia during breast cancer development (tumorigenesis), as well as a potential role in breast cancer. In recent studies, the ras oncogene, acting through the mitogen-activated protein kinase (MAPK) pathway, was shown to induce cyclin D1 by acting on cyclin D1 promoter (Albanese et al., 1995; Liu et al., 1995). Similarly, the neu oncogene, which is known to operate upstream of ras, upregulates the promoter of the cyclin D1 gene (Lee et al., 2000). Our data suggest that the Jak2/STAT5b pathway, as well as the Neu-Ras pathway is required in order to control overexpression of cyclin D1 in breast cancer cells.

In more recently studies, cyclin D1 was shown to be a direct target gene for STATs. In F-36P cells, IL-3 induced cyclin D1 expression was shown to be inhibited by dominant negative-STAT5, while constitutively activated-STAT5 induced IL-3 independent cyclin D1 promoter activity (Simonart et al., 2000). Indeed, the cyclin D1 promoter was shown to contain binding sites for STAT3 and -5 (Bromberg et al., 1999; Matsumura et al., 1999; de Groot et al., 2000). Our results show that like IL-3, hypoxia induces STAT5 binding to the GAS1 in the cyclin D1 promoter as well as increased cyclin D1 promoter activity (Figure 5). Our results suggest that the STAT5-binding site (cyclin D1-GAS1) may be a critical target for the induction of cyclin D1 transcription by DFO or hypoxia in breast cancer cells, although several other regulatory elements such as binding sites for Sp1, Ets, CREB and E2F have also been identified in the promoter region of the cyclin D1 gene (Matsumura et al., 1999). These studies have demonstrated that hypoxia is able to regulate the cell cycle in breast cancer cells and have identified specific targets in this process. This model system will enable molecular dissection of the pathways involved in hypoxia- induced proliferation (Figure 6).

Our results indicate that hypoxia-induced STAT5b phosphorylation regulates the transcriptional activity of cyclin D1. Our data suggest that hypoxia may mediate the transcriptional regulation of cyclin D1 via the Jak2/STAT5b pathway. The STAT pathway plays a pivotal role in both inflammatory and immune responses. It is likely that this pathway contributes to the pathogenesis of mammary epithelial tumor and airway remodeling.

\section{Acknowledgement}

This work was supported by the Ministry of Commerce Industry and Energy through the Bio-Food and Drug Research Center at Konkuk University, Chungju, Korea.

\section{References}

Albanese C, Johnson J, Watanabe G, Eklund N, Vu D, Arnold A, Restell RG. Transforming p21 $1^{\text {ras }}$ mutants and c-Ets-2 activate the cyclin D1 promoter through distinguishable regions. J Biol Chem 1995;270:23589-97

Bando H, Toi M, Kitada K, Koike M. Genes commonly upregulated by hypoxia in human breast cancer cells MCF7 and MDA-MB-231. Biomed Pharmacother 2003;57:333-40

Bartkova J, Lukas J, Muller H, Lutzhoft D, Strauss M, Bartek J. Cyclin D1 protein expression and function in human breast cancer. Int J Cancer 1994;57:353-61

Bienvenu F, Gascan H, Coqueret O. Cyclin D1 represses STAT3 activation through a Cdk4-independent mechanism. J Biol Chem 2001;276:16840-7

Bowman T, Garcia R, Turkson J, Jove R. STATs in oncogenesis. Oncogene 2000;19:2474-88

Brahimi-Horm C, Berra E, Pouyssegur J. Hypoxia: the tumor's gateway to progression along the angiogenic pathway. Trends Cell Biol 2001;11:S32-6

Brockman JL, Schroeder MD, Schuler LA. PRL activates the cyclin D1 promoter via the Jak2/Stat pathway. Mol Endocrinol 2002;16:774-84

Bromberg JF, Wrzeszczynska MH, Devgan G, Zhao Y, Pestell RG, Albanese C, Darnell JE Jr. Stat3 as an oncogene. Cell 1999;98:295-303

de Groot RP, Radijmakers JA, Lammers JW, Koenderman L. STAT5-Dependent Cyclin D1 and Bcl-xL Expression in Bcr-Abl-Transformed Cells. Mol Cell Biol Res Commun 2000;3:299-305

Frasor J, Barkai U, Zhong L, Fazleabas AT, Gibori G. PRLinduced ER $\alpha$ gene expression is mediated by Janus kinase 2 (Jak2) while signal transducer and activator of transcription $5 \mathrm{~b}$ (Stat5b) phosphorylation involves Jak2 and a second tyrosine kinase. Mol Endocrinol 2001;15:1941-52

Fukuchi K, Tomoyasu S, Tsuruoka N, Gomi K. Iron deprivation-induced apoptosis in HL-60 cells. FEBS Lett 1994; 350:139-42

Grimley PM, Dong F, Rui H. Stat5a and Stat5b: fraternal twins of signal transduction and transcriptional activation. Cytokine Growth Factor Rev 1999;10:131-57

Harris AL. Hypoxia a key regulatory factor in tumor growth. 
Nat Rev Cancer 2002;2:38-47

Ihle JN. Cytokine receptor signaling. Nature 1995;377:591-4 Joung YH, Park JH, Park TK, Lee CS, Kim OH, Ye SK, Yang UM, Lee KJ, Yang YM. Hypoxia activates signal transducers and activators of transcription 5 (STAT5) and increases its binding activity to the GAS element in mammary epithelial cells. Exp Mol Med 2003;35:350-7

Kabotyanski EB and Rosen JM. Signal transduction pathways regulated by prolactin and Src result in different conformations of activated Stat5b. J Biol Chem 2003;278: 17218-27

Kazansky AV, Kabotyanski EB, Wyszomierski SL, Mancini MA, Rosen JM. Differential effects of prolactin and src/abl kinases on the nuclear translocation of STAT5B and STAT5A. J Biol Chem 1999;274:22484-92

Kim DM, Yang KM, Yang BS. Biochemical characterizations reveal different properties between $C D K 4 /$ cyclin D1 and CDK2/ cyclin A. Exp Mol Med 2003;35:421-30

Lee MY, Joung YH, Lim EJ, Park JH, Ye SK, Park TK, Zhang $Z$, Park DK, Lee KJ, Yang YM. Phosphorylation and activation of STAT proteins by hypoxia in breast cancer cells. Breast 2005;in press (E-pub)

Lee RJ, Albanese C, Stenger RJ, Watanabe G, Inghirami G., Haines GK 3rd, Webster M, Muller WJ, Brugge JS, Davies RJ, Pestell RG. pp60(v-src) induction of cyclin D1 requires collaborative interactions between the extracellular signalregulated kinase, p38, and Jun kinase pathways. A role for cAMP response element-binding protein and activating transcription factor-2 in pp60(v-src) signaling in breast cancer cells. J Biol Chem 1999;274:7341-50

Lee RJ, Albanese C, Fu M, D'Amico M, Lin B, Watanabe G, Haines GK 3rd, Siegel PM, Hung MC, Yarden Y, Horowitz JM, Muller WJ, Pestell RG. Cyclin D1 is required for transformation by activated $\mathrm{Neu}$ and is induced through an E2F-dependent signaling pathway. Mol Cell Biol 2000; 20:672-83

Leonard WJ and O'Shea JJ. Jaks and STATs: biological implications. Annu Rev Immunol 1998;16:293-322

Liu JJ, Chao JR, Jiang MC, Ng SY, Yen JJ, Yang-Yen HF. Ras transformation results in an elevated level of cyclin D1 and acceleration of $\mathrm{G} 1$ progression in NIH 3T3 cells. Mol Cell Biol 1995;15:3654-63

Liu X, Robinson GW, Wagner KU, Garrett L, Wynshaw-Boris A, Hennighausen L. Stat5a is mandatory for adult mammary gland development and lactogenesis. Genes Dev 1997; 11:179-86

Matsumura I, Kitamura T, Wakao H, Tanaka H, Hashimoto K, Albanese C, Downward J, Restell RG., Kanakura Y. Transcriptioal regulation of the cyclin D1 promoter by STAT5: its involvement in cytokine-dependent growth of hematopoietic cells. EMBO J 1999;18:1367-77

Musgrove EA, Lee CS, Buckley MF, Sutherland RL. Cyclin D1 induction in breast cancer cells shortens $\mathrm{G} 1$ and is sufficient for cells arrested in $\mathrm{G} 1$ to complete the cell cycle. Proc Natl Acad Sci USA 1994;91:8022-6
O'Shea JJ, Gadina M, Schreiber RD. Cytokine signaling in 2002: new surprises in the Jak/Stat pathway. Cell 2002; 109:S121-31

Park JH, Lee HY, Roh SC, Kim HY, Yang YM. Screening of Differentially Expressed Genes by Desferrioxamine or Ferric Ammonium Citrate Treatment in HepG2 Cells. J Biochem Mol Biol 2000;33:396-401

Park JH, Park TK, Kim HY, Yang YM. The IGFBP-1 mRNA Expression in HepG2 Cells is Affected by Inhibition of Heme Biosynthesis. J Biochem Mol Biol 2001a;34:385-9

Park SH, Yamashita H, Rui H, Waxman DJ. Serine phosphorylation of $\mathrm{GH}$-activated signal transducer and activator of transcription 5a (STAT5a) and STAT5b: Impact on STAT5 transcriptional activity. Mol Endocrinol 2001b;15:2157-71

Pellegrini $S$ and Dusanter-Fourt I. The structure, regulation and function of the Janus kinases (JAKs) and the signal transducers and activators of transcription (STATs). Eur $\mathrm{J}$ Biochem 1997; 248:615-33

Pircher TJ, Petersen H, Gustafsson JA, Haldosen LA. Extracellular signal-regulated kinase (ERK) interacts with signal transducer and activator of transcription (STAT) $5 a$. Mol Endocrinol 1999;13:555-65

Schindl M, Schoppmann SF, Samonigg $H$, Hausmaninger $H$, Kwasny W, Gnant M, Jakesz R, Kubista E, Birner P, Oberhuber G. Austrian Breast and Colorectal Cancer Study Group. Overexpression of hypoxia-inducible factor 1alpha is associated with an unfavorable prognosis in lymph nodepositive breast cancer. Clin Cancer Res 2002;8:1831-7

Schroeder MD, Symowicz J, Schuler LA. PRL modulates cell cycle regulators in mammary tumor epithelial cells. Mol Endocrinol 2002;16:45-57

Simonart T, Degraef C, Andrei G, Mosselmans R, Hermans $P$. Iron chelators inhibit the growth and induce the apoptosis of Kaposi's sarcoma cells and of their putative endothelial precursors. J Invest Dermatol 2000;115:893-900

Simon AR, Takahashi S, Severgnini M, Fanburg BL, Cochran BH. Role of the JAK-STAT pathway in PDGFstimulated proliferation of human airway smooth muscle cells. Am J Physiol Lung Cell Mol Physiol 2002;282:L1296L304

Storz P, Doppler H, Pfizenmaier K, Muller G. Insulin selectively activates STAT5b, but not STAT5a, via a JAK2independent signalling pathway in Kym-1 rhabdomyosarcoma cells. FEBS Lett 1999;464:159-63

Tazuke SI, Mazure NM, Sugawara J, Carland G, Faessen GH, Suen LF, Irwin JC, Powell DR, Giaccia AJ, Giudice LC. Hypoxia stimulates insulin-like growth factor binding protein 1 (IGFBP-1) gene expression in HepG2 cells: a possible model for IGFBP-1 expression in fetal hypoxia. Proc Natl Acad Sci USA 1998; 95:10188-93

Udy GB, Towers RP, Snell RG, Wilkins RJ, Park SH, Ram PA, Waxman DJ, Davey HW. Requirement of STAT5b for sexual dimorphism of body growth rates and liver gene expression. Proc Natl Acad Sci USA 1997;94:7239-44 
Wang TC, Cardiff RD, Zukerberg L, Lees E, Arnold A, Schmidt EV. Mammary hyperplasia and carcinoma in MMTVcyclin D1 transgenic mice. Nature 1994;369:669-71

Yamashita H, Nevalainen MT, Xu J, LeBaron MJ, Wagner KU, Erwin RA, Harmon JM, Hennighausen L, Kirken RA, Rui $H$. Role of serine phosphorylation of Stat5a in prolactin- stimulated $\beta$-casein gene expression. Mol Cell Endocrinol 2001;183:151-63

Yu Q, Geng Y, Sicinski P. Specific protection against breast cancers by cyclin D1 ablation. Nature 2001;411:1017-21 